\title{
O discurso e a cidade sob os olhares de Ralfo, narrador de Sérgio Sant'Anna
}

\author{
Ana Paula Teixeira Porto*
}

\begin{abstract}
Resumo: Este trabalho apresenta reflexões sobre a representação da cidade no romance Confissões de Ralfo, de Sérgio Sant'Anna. Tem o objetivo de discutir como a fragmentação da forma relaciona-se à configuração da cidade moderna e do homem e baseia-se em reflexões de Adorno, Pesavento, Ginzburg, Lynch, Shollhammer, entre outros. A pesquisa mostra que o romance consegue integrar à história do personagem (Ralfo) história cultural urbana, produzindo representações da cidade que traduzem sensibilidades e sociabilidades do homem no contexto da cidade moderna.
\end{abstract}

Palavras-chave: cidade; Sergio Sant'Anna; Confissões de Ralfo

\begin{abstract}
This paper presents some reflections on the representation of the city in Confissões de Ralfo, by Sérgio Sant'Anna. It aims at discussing the literary form and its relation with the modern city and the man. The work is based on reflections of Adorno, Pesavento, Ginzburg, Lynch and Shollhammer. The book by Sergio Sant'Anna integrates the story of Ralfo and the urban cultural history and produces representations of the city that translate the sensitivity and sociability of the man in the context of the modern city.
\end{abstract}

Keywords: city; Sergio Sant'Anna; Confissões de Ralfo

Organizada em uma estrutura externa "atipicamente complexa e fragmentária", como define Malcolm Silverman (1981, p. 293), a construção formal de Confissões de Ralfo, de Sérgio Sant'Anna, constitui um objeto estético tão múltiplo como o são as possibilidades de observá-lo criticamente. Ao leitor são narradas imaginárias e reais peripécias de um "personagem à procura de seus acontecimentos", Ralfo, cujas histórias e representações são marcadas por dialogismo, fragmentação, simulacros, que configuram uma narrativa dupla, tanto nos aspectos estéticos quanto nos temáticos. Assim, as representações literárias da obra oportunizam ao crítico possibilidades de "desleituras" que podem estar concentradas na configuração do narrador, na intercalação de gêneros, nas relações entre História e literatura, no diálogo da obra com a literatura brasileira de sua época, nas relações intertextuais com outras obras de arte, na configuração do imaginário da cidade no romance, entre tantas alternativas de discussão do texto literário.

\footnotetext{
* Doutoranda UFRGS.
} 
Considerando a necessidade de delimitar um enfoque para desenvolver um trabalho analítico, opta-se pela fragmentação. Esta, além de exercer papel determinante nas obras literárias do século XX, como aponta Anatol Rosenfeld (1996), é um recurso que dá margem para interpretação das relações entre forma, conteúdo e representações de imaginárias da cidade. É um elemento significativo para compreender como o narrador de Sérgio Sant'Anna articula tendências temáticas com opções formais, entrecruzando observações argutas filtradas pelo senso crítico de análise social.

Como o discurso narrativo do texto é pautado na estratégia da simulação (traço recorrente nos romances do escritor), a fragmentação, anunciada na abertura do livro, pode ser apenas um traço aparente do romance. Constituída por um prólogo, nove livros (subdivididos em trinta e dois capítulos), um epílogo e uma nota final, a obra Confissões de Ralfo: uma autobiografia imaginária, de Sérgio Sant'Anna, pode ser lida como unidades independentes, já que as três dezenas de histórias apresentam uma autonomia no sentido de que a significação de cada unidade não está necessariamente presa aos demais segmentos que compõem a narrativa. Mas também pode ser lida como um texto fragmentado, cujas partes somam-se e associam-se para construir passagens plenas de significação, cambiantes conforme o olhar do leitor, já que a composição da obra é tão múltipla quanto as possibilidades de interpretação.

Nessa perspectiva, a leitura que se desenvolve neste trabalho está direcionada à fragmentação da obra, pela qual tramita a representação da cidade na obra do escritor. $\mathrm{O}$ estudo procura discutir as articulações entre o imaginário social da cidade e a constituição da forma fragmentária do romance. Assim, interessa refletir sobre os discursos e a(s) imagem(s) da(s) cidade(s) no texto, enfatizando "imaginários sociais" a que os personagens fazem alusão e comparando estas representações com a perspectiva crítica que envolve o livro. As reflexões estão baseadas em uma pesquisa bibliográfica, fundamentada em autores como Theodor Adorno, Rosa de Carvalho, Sandra Pesavento, Anatol Rosenfeld, entre outros, os quais discutem concepções da narrativa fragmentada e da configuração da cidade na literatura.

A estrutura fragmentada do romance de Sérgio Sant'Anna, articulada ao enredo, constitui um objeto para análise fecunda da representação da cidade. O texto literário do escritor pode ser compreendido segundo a perspectiva de Sandra Pesavento, que destaca que este olhar interpretativo "implica pensar a literatura como uma leitura específica do urbano, capaz de conferir sentidos e resgatar sensibilidades aos cenários citadinos, às suas ruas e formas arquitetônicas, aos seus personagens e às sociabilidades que nesse espaço têm lugar" (1999, p. 10). Assim, o texto literário através da fragmentação da forma pode criar cidades fictícias (e por que não reais?), “traduzidas em palavras e figurações mentais imagéticas do 
espaço urbano e de seus atores" (PESAVENTO, 1999, p. 10). Considerando essa premissa, cabe discutir a representação da cidade no romance de Sérgio Sant'Anna, entendendo-a como um espaço imaginário (produto da invenção do discurso de Ralfo), podendo, em certo sentido, ser visto como representação de uma cidade moderna.

\section{Confissões de Ralfo e a representação da cidade}

Através de uma linguagem elaborada de modo a fundir o culto e o coloquial, o cerimonioso e o debochado, o irônico e o cômico, a obra narra as peripécias de Ralfo, definido como "Cavaleiro de boas e péssimas intenções", "o homem sem pai e sem pátria" (SANT'ANNA, 1995, p. 13), que vive uma aventura por cidades e países imaginários, uma vez que, à exceção das cidades de São Paulo e Santos e dos países Brasil, França e Espanha, os espaços do romance são produtos da invenção. A indicação dos espaços serve para mostrar que as artimanhas de Ralfo são desenvolvidas no cenário citadino e sinaliza o espaço como uma espécie de pano de fundo para conferir sentidos ao imaginário urbano e social.

Em geral, o discurso do narrador aponta algumas especificidades do urbano tanto em seus aspectos físicos quanto humano, embora não se preocupe em definir a arquitetura, as ruas, os limites geográficos das cidades. Logo no início do romance, algumas referências ao espaço onde são realizadas as cenas chamam atenção. Enquanto Ralfo exerce a função de guia turístico (uma profissão provisória, uma vez que Ralfo desempenha vários “eus”), ressalta traços do ambiente em que está, traduzindo, em palavras e figurações mentais imagéticas, o espaço urbano:

Lojas de mau gosto. Bares e bancos. Edifícios. Aqui neste local, meus caros turistas, o acontecimento histórico mais importante foi um funcionário público que se atirou do vigésimo andar, por causa de dívidas, alcoolismo e amores frustrados. Um homem sem importância, ninguém prestou atenção nele, embora tivessem cercado o cadáver. Mas as pessoas queriam ver apenas as tripas, o espetáculo, e não o homem, que mereceu umas poucas linhas amareladas de jornal (SANT'ANNA, 1995, p. 14).

Através de frases curtas organizadas com uma linguagem formal, própria do discurso de um guia, Ralfo, neste excerto, traz uma apresentação inicial do imaginário urbano pelo qual transita. Sem nomear a qual cidade se refere, o personagem sublinha pontos específicos do lugar, como lojas, bares, edifícios e bancos. Estes elementos configuram uma cidade moderna, sinalizando que, quanto ao tempo histórico dos acontecimentos, a obra se passa no contexto moderno, cujas edificações são facilmente encontradas. A referência à cidade moderna também é perceptível porque Ralfo sublinha imagens fragmentadas da cidade, cujas 
informações são dadas de modo dispersivo, acumulando visões heterogêneas sobre o espaço urbano.

Adrián Gorelik (1999) discute a representação da cultura urbana na modernidade e destaca que há, nesse sentido, produção de diversas imagens e figuras, muitas com posições contrapostas e visões incomunicáveis entre si. Sob esta perspectiva, a paisagem urbana aparece como uma justaposição de artefatos efêmeros com restos de infra-estrutura decadente, fábricas abandonadas, moradias precárias, etc. Essas imagens do cenário urbano moderno enfatizam o contraste e a desigualdade, construindo "a leitura cultural da cidade como ruína da modernidade" (GORELIK, 1999, p. 77). O esclarecimento de Gorelik pode ser um argumento para explicar por que, na obra de Sérgio Sant'Anna, a representação do imaginário da cidade está articulada a uma concepção moderna do espaço urbano, uma vez que Ralfo aponta diversas imagens das cidades, que sinalizam "ruínas", aspectos degradantes, tais como: pontos comerciais de "mau gosto"; indiferença do homem ao homem; violência. Essas imagens são retomadas continuamente em outros fragmentos que fazem alusão à cidade, destacando fruições negativas do espaço urbano.

Além disso, o fragmento destaca que, no espaço urbano, o imaginário social é pautado por edificações não apenas físicas (os prédios), mas humanas. A cena de suicídio do funcionário público mostra, além do cenário, as características do homem urbano, que pára sua rotina para "ver apenas as tripas, o espetáculo, e não o homem" (SANT'ANNA, 1995, p. 14). Ou seja, o relato de Ralfo salienta a indiferença do homem ao outro, uma vez que as pessoas queriam ver o cadáver (o aspecto físico) e não se interessaram em conhecer causas e conseqüências do ato do funcionário público. A passagem enfatiza também a busca pela "diversão" (espetáculo) ao presenciar cenas de violência e morte, pois "ninguém prestou atenção nele" (SANT'ANNA, 1995, p. 14), numa alusão à morte e à violência como acontecimentos banais, sem muita importância.

A referência a dívidas, alcoolismo e amores frustrados também é significativa para compreender a representação da cidade. A justaposição destas palavras sugere que o homem urbano convive não apenas com as paredes dos edifícios, mas também com "paredes psicológicas" que tornam o ser humano desequilibrado. Na perspectiva de Roberto Guiducci (1980), na cidade o homem não encontra apenas o problema relativo à opção de trabalho e habitação, uma vez que também enfrenta impasses para o seu desenvolvimento comunicativo e psicológico, os quais violam os pressupostos mínimos para fazer do homem um ser social. Segundo o autor: 
O habitante da cidade, uma vez resolvido o problema do trabalho e da habitação no sacrifício de qualquer outro espaço, encontra-se não somente diante de uma série ininterrupta de paredes de cimento como também diante de paredes psicológicas que impedem um desenvolvimento normal da infância, a possibilidade de comunicações com a vizinhança, a capacidade de alternativas de experiência, de onde surgem as neuroses, a insegurança, a instabilidade, a claustrofobia, a despersonificação, sem que as vantagens da cidade possam compensar estas perdas que incidem no interior profundo do homem e não lhe permitem um desenvolvimento equilibrado (GUIDUCCI, 1980, p. 89).

A narrativa de Ralfo pode ser lida como um indício de que o homem, no contexto urbano, tem ofuscado sua capacidade comunicativa, da qual surge a interação. $O$ fragmento "Ninguém prestou atenção nele" mostra que não há interesse em estabelecer vínculos com o ser social, restando apenas a necessidade egocêntrica de "ver o cadáver". Isto é, o homem da cidade moderna está habituado a não se comunicar, a não dialogar e estabelecer vínculo com o outro e, conseqüentemente, a não se importar com a realidade alheia, vivendo, assim, numa espécie de "clausura" de si mesmo (o olhar volta-se somente para si, ressalvando-se de uma abertura ao outro). Novamente o texto literário retoma "perdas", ruínas da cidade moderna, cujo espaço leva à instabilidade, à desestruturação da "parede psicológica". Isso poderia explicar a opção por suicídio do funcionário público relatada por Ralfo.

Também se deve apontar que a apresentação da cidade aos turistas serve não apenas para Ralfo exercer sua função profissional temporária, mas também para destacar a presença de um observador crítico que não se contém em apenas descrever o cenário, pois aproveita o momento para pincelar uma crítica sutil às estratégias de segurança adotadas pelo poder público:

À vossa frente, senhoras e senhores, se fixardes os olhos no alto daquela avenida, temos o Palácio do Governo, que serve de moradia e local de trabalho àquele que tão sabiamente governa este Estado. Quanto às grades de ferro pontudo e também os soldados armados e os cães, não se impressionem os distintos visitantes, pois trata-se apenas de uma pequena precaução. Porque há sempre aqueles que respondem com ódio ao amor de seus superiores. Uma ínfima minoria, mas perigosa de qualquer modo e que não convém subestimar. (SANT'ANNA, 1995, p. 145)

A exposição de Ralfo traz outro aspecto significativo da composição da cidade: a violência e a insegurança. Com pitadas de ironia ao referir-se ao poder público, Ralfo enfatiza o uso de equipamentos de proteção (grades de ferro pontudo), profissionais de segurança (soldados armados) e animais preparados (cães) para ajudar a reprimir o crime. Nesse sentido, a descrição do Palácio do Governo constitui um exemplo de configuração da cidade como um espaço de medo, pois os habitantes necessitam prevenir-se contra possíveis comportamentos criminosos. A violência, já exposta no trecho que cita o suicídio de um funcionário público, é reiterada sob um novo ângulo: a violência à propriedade. 
A violência, assim, está ligada também à falta de proteção de móveis e imóveis. Além de o homem conviver, na cidade moderna, com o desequilíbrio psicológico, a instabilidade, um cenário decadente, também tem de acostumar-se com a possibilidade de suas moradias e locais de trabalho constituírem "refúgio" daqueles que buscam ascensão econômica com base no trabalho alheio. Sob este ponto de vista, o texto literário reforça o símbolo da cidade moderna como espaço de insegurança, instabilidade, perigo, enfim, imagens negativas do espaço urbano.

A referência à violência é fator que comprova a ênfase dada pelo texto à negatividade do espaço urbano, ameaçado pelo crime. A leitura do texto indica também que a violência, característica da cidade moderna e multifacetada sob diversas perspectivas, cessa a liberdade humana que, conseqüentemente, gera solidão, incomunicabilidade, medo, insegurança. Assim, o discurso de Ralfo procura alertar para o fato de que, "Nestas condições de vida, a liberdade se transforma em repressão, a facilidade de relacionamento, em solidão, a oferta de ocasiões, em insegurança e medo" (GUIDUCCI, 1980, p. 90). O trecho a seguir, que relata um passeio de Ralfo com Rute (uma suposta namorada do personagem), reforça esta possibilidade de leitura:

\begin{abstract}
Nossos passeios desordenados pelas ruas dessa cidade. Uma cidade fantasma, Rute. Passos ritmados de um policial invisível durante a noite. Multidões súbitas e silenciosas durante o dia e que de repente desaparecem para ceder lugar a gatos negros e uivantes, cachorros esqueléticos que se afundam em latas de lixo e habitantes lúgubres saídos de pesadelos. Grupos de pessoas exageradamente pintadas, como arlequins e pierrôs. Gritos de terror dentro da noite, gargalhadas, alto-falantes ocultos a transmitirem hinos marciais e músicas dissonantes. Uma cidade que não podemos decifrar, porque a cada dia, cada hora que passa, parece ter mudado. Uma cidade que, pressentimos, pode desfazer-se com seus habitantes (SANT'ANNA, 1995, p. 70).
\end{abstract}

Ralfo também parece ressaltar o caráter universalizante da cidade, pois não a nomeia, e, quando o faz, utiliza nomes que serviriam de arquétipos para representação de qualquer metrópole (São Paulo, por exemplo, como é citado em um excerto do livro). O uso dos artigos indefinidos pode fazer alusão a uma deficiência física das cidades modernas apontada por Lynch (1972): a ilegibilidade. Este traço refere-se à falta de características singulares da cidade e à dificuldade de compreensão de sua linguagem:

Quando as partes da cidade não têm relação visível entre si, sua incoerência pode contribuir
para um sentimento de alienação de se estar perdido em um meio com o qual não é possível
manter nenhum tipo de diálogo. Nossas cidades apresentam muitas ambigüidades, confusões e
descontinuidades; as atividades significativas não são possíveis de apreciação; a história e a
base natural são obscurecidas. A linguagem da cidade é tão difícil de compreender como uma
notícia de jornal (LYNCH, 1975, p, 209).

No contexto moderno, conhecer a cidade, segundo a perspectiva de Lynch, é difícil, pois as diferenças (dissonâncias) das partes que a compõem impedem que o homem a 
compreenda e reconheça sua singularidade. Esse traço parece ser incorporado na visão de Ralfo, pois ele destaca que está em "Uma cidade que não podemos decifrar". A cidade é, então, um enigma, um espaço composto por descontinuidades, fragmentações e ambigüidades, que podem referir-se a qualquer espaço urbano, pois a cidade não tem uma identidade própria.

Outro momento da obra de Sérgio Sant'Anna em que o imaginário da cidade se destaca é a narração da passagem de Ralfo por Eldorado (uma referência a Cuba). O atentando que Ralfo sofrera em Eldorado instiga as autoridades da cidade a enviá-lo, de páraquedas, para Goddamn City para que "Ralfo, Primeiro e Único" não fosse aclamado pelo povo nem edificado como mártir. A cidade, definida pelo personagem como "A Cidade Elétrica” (SANT'ANNA, 1995, p. 83), é apresentada através de um texto de guia turístico que registra dados específicos do lugar (como rede de hotelaria e transportes, população, situação geográfica e atrações turísticas) e sublinha comentários sobre o urbanismo exagerado e o comportamento da população.

Quanto às possibilidades de compra no comércio, o narrador enfatiza: "Desde os mais completos computadores e armas [...] até mulheres de plásticos e afáveis cães eletrônicos, que possuem a conveniência de não latirem e nunca sujarem a casa.” (SANT’ANNA, 1995, p. 78). A referência do narrador aponta traços positivos da cidade, como a facilidade para comprar objetos variados (mesmo que isto seja viável apenas para aqueles que possuem poder aquisitivo suficiente para levar para casa os objetivos que desejar). Destaca também tecnologia avançada, o que, se comparado ao ambiente rural, pode ser considerado um aspecto positivo da cidade moderna.

Em relação às praias de Goddamn City, Ralfo salienta: "Infelizmente, somos obrigados a confessar que, em razão de detritos acumulados durante décadas em suas águas, as belas praias de Goddamn City estão ali para ser vistas e não desfrutadas" (SANT'ANNA, 1995, p. 78). Os dois trechos novamente sublinham aspectos negativos do cenário urbano, e, somando-se aos demais excertos, o saldo do imaginário da cidade pode ser traduzido em ruínas, como o próprio nome da cidade descrita enfatiza.

Os traços levantados no roteiro para definir a urbe são ressaltados por duas estratégias: a relação intertextual com o cenário dos filmes de Batman - Gothan City, a metrópole violenta protegida pelo Homem-Morcego; e a nomeação dada ao lugar - Goddamn City, cujo significado da expressão (cidade maldição de Deus) traz indícios da performance de seus habitantes, justificando a impressão do personagem: 
Ralfo procurou desembaraçar-se rapidamente do pára-quedas, mas logo se espantando porque as pessoas não lhe prestavam a menor atenção, como se fosse habitual uma pára-quedista descer sobre as ruas principais de Goddamn City. Como também não prestavam atenção ao negro assassinado, como se fosse habitual o fato de encontrar-se um negro morto no centro da cidade. Como se qualquer coisa fosse habitual em Goddamn City. (SANT’ANNA, 1995, p. 89).

Ao mesmo tempo em que a figuração imaginária da cidade tem como lema o progresso e diversos pontos atrativos, ela é representada também com traços negativos, confirmando uma expressão contraditória que configura a cidade moderna. Para Sandra Pesavento, a metrópole traz uma contradição: por um lado, é luz, sedução, meca da cultura, civilização; "por outro, pode ser representada como ameaçadora, centro de perdição, império do crime e da barbárie, mostrando uma faceta de insegurança e medo para quem nela habita." (PESAVENTO, 1999, p. 19) Os atrativos comerciais da cidade, as cenas de violência e o aprisionamento do homem em sua própria casa, como mostram os trechos em que Ralfo enfatiza o uso de grades de proteção residencial, sublinham a perspectiva contraditória de representação da cidade defendida por Pesavento (1999). Ralfo pode ser caracterizado como um observador que capta a dualidade da urbe, uma contradição que parece ser "natural", algo que passa a ser incorporado na rotina dos habitantes sem que estes parem para refletir sobre o cenário em que vivem.

As cidades imaginárias ou não, com nome ou sem nome dado pelo personagem, podem ser sintetizadas por uma descrição significativa quanto ao espaço das cenas:

Uma cidade próxima, de tamanho médio, que se revela: casas, automóveis, luzes que se acendem. Uma cidade e todas as suas coordenadas e sistemas aleatórios; um nexo que seus habitantes pensam existir, mas, na verdade, não existe. $\mathrm{O}$ nome das ruas e os números das casas apenas disfarçam um não-sistema absolutamente sem ordem. Uma cidade é o conjunto dissonante e casual de movimentos e ruídos, dentro de um tempo marcado por esse movimento que nunca termina. Ou mesmo terminará, algum dia (SANT'ANNA, 1995, p. 172).

Num movimento que acentua a idéia de continuidade das cenas típicas de uma cidade qualquer, a narração de Ralfo parece traduzir, além das dissonâncias da cidade moderna, uma necessidade de fragmentar a própria representação tanto da cidade quanto das histórias "vividas" ou imaginadas pelo personagem central. As imagens simbólicas da cidade são apresentadas em fragmentos dispersos que funcionam como aporte para narração das peripécias do narrador-personagem.

Sob este ponto de vista, a fragmentação da narrativa pode ser lida como um recurso explorado para acentuar as contradições de Ralfo e suas incertezas, as quais ganham maior ênfase se associadas à representação também dissonante da cidade, que funciona como pano de fundo para as ações do personagem. Nesta conjuntura, a construção das cenas fragmentadas ainda permite perceber uma visão de cidade onde o homem parece abster-se de 
valores, sentimentos, humanização. Portanto, a representação fragmentada da cidade alude ainda a uma referência da posição do homem no contexto moderno.

\title{
2 Cidade e fragmentação: um olhar sobre a cidade sem alma
}

Ao discutir a configuração da forma artística no contexto moderno, Theodor Adorno (1982) e Anatol Rosenfeld (1996) sinalizam a emergência de novos "moldes" de composição narrativa nesse século, defendo a tese de que as artes modernas, entre as quais a literária, assimilam na própria estrutura uma forma de representação da realidade histórico-cultural de seu tempo. O trecho a seguir, de Rosenfeld, sintetiza esta afirmação:

Mas sem dúvida se exprime na arte moderna uma nova visão do homem e da realidade ou, melhor, a tentativa de redefinir a situação do homem e do indivíduo, tentativa que se revela no próprio esforço de assimilar, na estrutura da obra-de-arte (e não apenas na temática), a precariedade da posição do indivíduo no mundo moderno (1996, p. 97).

Na perspectiva de Theodor Adorno e Anatol Rosenfeld, não são apenas as tendências temáticas os índices de significação de uma obra de arte. $\mathrm{O}$ tratamento estético dado aos temas constitui também fonte de significação e, portanto, não deve ser desprezado na interpretação de um texto literário. Através de uma concepção dialética, Theodor Adorno (1982) desenvolve uma reflexão teórica acerca da necessidade de, no exercício de leitura das obras de arte, não se deter apenas no conteúdo nem apenas na forma - é a combinação forma/conteúdo que constitui as matizes para a interpretação, pois, conforme Theodor Adorno, a realização formal também desempenha uma função específica para atribuição de um sentido à arte. Ao discorrer sobre a relação da arte com a realidade empírica, o pensador afirma que a forma estética é um conteúdo sedimentado:

\begin{abstract}
A arte nega as determinações categorialmente impressas na empiria e, no entanto, encerra na sua própria substância um ente empírico. Embora se oponha à empiria através do momento da forma - e a mediação da forma e do conteúdo não deve conceber-se sem a sua distinção importa, porém, em certa medida e geralmente, buscar a mediação do facto de a forma estética ser conteúdo sedimentado (1982, p. 15).
\end{abstract}

Além de sublinhar o âmbito formal como elemento de significação, Theodor Adorno associa a representação artística a fatos sociais, concebendo a obra tanto como um "ente autônomo" quanto um "fato social". Para o teórico, as obras de arte apresentam uma ligação com a realidade exterior, sendo que "A ponta que a arte volta para a sociedade é, por seu turno, algo de social" (ADORNO, 1982, p. 46) e que a relação da obra com o dado social é mediada pela realização formal, uma vez que a penetração dos fatores externos é incorporada ao plano estético. Nesse sentido, adquire valor a obra de arte que trabalha esteticamente os dados externos em sua própria estrutura, pois "nas suas reflexões estéticas ele [Theodor 
Adorno] condenara o engajamento direto (do tipo brechtiano) e privilegiou o trabalho crítico com a forma" (SELIGMANN-SILVA, 2003, p. 48).

A partir do "conteúdo estético", as obras de arte podem manter relações com a realidade sócio-histórica, visto que "O momento histórico é constitutivo nas obras de arte" (ADORNO, 1982, p. 207). Discorrendo sobre problemas de estética e suas relações com o social, Theodor Adorno (1982) chama atenção para os episódios históricos das catástrofes e afirma a existência de vínculos entre as experiências de barbárie do século XX e as produções artístico-culturais (música, teatro, literatura). Essas relações, mediatizadas através da forma, para alcançar efeito ativo e crítico, devem abster-se da objetividade e da organização lógica e linear, pois a arte que se baseia nesses traços não chega à essência nem alcança sua condição social de modo satisfatório. Nesse sentido, o filósofo destaca que "Quanto mais o trabalho social contido na obra de arte se objetiva e plenamente se organiza, tanto mais soa a oco e se torna estranha a si mesma" (1982, p. 119).

Considerando que o processo histórico não é construído linearmente, já que se configura a partir de conflitos, Theodor Adorno formula a impossibilidade da harmonia na sociedade. A sociedade para ele é marcada por conflitos e contradições. Como a arte está intimamente ligada aos condicionamentos da ordem social, as obras que chegam a essa posição quanto ao histórico-social não conseguem manter uma estrutura harmônica, linear e, nesse sentido, rompem com a objetividade, a linearidade e as concepções tradicionais de composição. Assim, manifesta-se a recusa aos padrões tradicionais de composição não só na estrutura da obra literária, que passa a ser pautada na não-linearidade discursiva, mas também na forma como o narrador representa os "fatos".

Combinando reflexões sobre arte, sociedade e estética, Theodor Adorno (1982) discorre sobre a posição do narrador no romance contemporâneo e mostra que o narrador perde a objetividade, característica dos textos realistas, e não aparece configurado de forma estruturada. Para o teórico, a narração objetiva pressupõe que os eventos sociais e históricos são simples, e, nesse sentido, ao marcar o discurso pela objetividade, o romance distorce a experiência humana, uma vez que ela é complexa e contraditória. A proposta do crítico é a de rejeitar a objetividade dos relatos para que o romance possa representar a essência do processo social da vida: "Se o romance quer permanecer fiel à sua herança realista e dizer como realmente são as coisas, então ele tem de renunciar a um realismo que, na medida em que reproduz a fachada, só serve para ajudá-la na sua tarefa de enganar" (ADORNO, 1982, p. 270). 
Da mesma forma que os temas mostram-se desarticulados, o discurso do narrador configura-se a partir de uma perspectiva que não obedece a uma ordem objetiva que explicite os princípios de causa-efeito. Exemplar da recusa à objetividade e ao discurso contínuo são as referências ao imaginário social da cidade. A capacidade de o personagem descrever o cenário da urbe a partir de pequenas inserções de comentários e referências se concilia com o trabalho jornalístico, que consiste em buscar informações significativas sobre um tema e tratá-las com objetividade, captando o que é mais significativo. Esta observação parece ser apropriada a uma das profissões de Ralfo, a de jornalista, que está "Sempre com um bloco de notas na mão, como um repórter" (SANT'ANNA, 1995, p. 42). Esta referência sinaliza a busca de Ralfo por flagrantes, por imagens e informações pertinentes que possam ter significados importantes para o contexto, mas que não apresentam explicitamente uma relação com sua própria autobiografia.

Considerando que "Existe uma relação direta entre a fragmentação formal em obras literárias e uma série de processos histórico-sociais que atingiram profundamente as relações entre os seres humanos e abalaram a concepção clássica de sujeito" (GINZBURG, 1999, p. 121), a fragmentação da forma do romance de Sérgio Sant'Anna pode ser examinada como elemento que possibilita, na estrutura do texto literário, representar contingências históricas e sociais do contexto brasileiro e mundial do século XX, em especial as representações da cidade moderna.

A fragmentação temática e estética da obra permite a percepção de um processo coeso, no sentido de que as estratégias do fragmento colaboram para uma visão crítico-social que se esconde por trás do caos: os capítulos, embora independentes, sinalizam um ritmo que traduz uma perspectiva amparada na possibilidade de chocar o leitor, incitando-o à reflexão, inclusive porque a dispersão das cenas e a descontinuidade discursiva impedem uma atitude passiva e tranqüila do leitor diante da matéria narrativa.

A violência constitui no romance do escritor um fator importante de configuração de uma imagem do social. Para Karl Shollhammer (2000), a literatura brasileira utiliza vários cenários para representação da violência como tema, sendo que, na literatura contemporânea, os espaços urbanos têm servido para essa proposta, diferentemente da literatura regionalista, que enfoca o campo, o sertão e o interior como cenário para essa discussão. Segundo o pesquisador, a ênfase no tema não se deve a uma exploração "simplista", mas a uma dimensão que articula literatura e cultura nacional:

A violência tem uma presença na literatura moderna que não permite reduzi-la a uma extravagância de gosto duvidoso ou aberração. Ao contrário, a violência aparece como constitutiva da cultura nacional, como elemento 'fundador'. Além de participar na 
simbolização da violência, a literatura procura nela um suporte para a experiência criativa que explora e transgride os limites expressivos da representação escrita (2000, p. 236).

A reiteração do tema da violência, tratado em diversos segmentos da obra e a partir de enfoques variados, amplia o conceito de violência. Ao abordar o assunto violência a partir de dimensões variadas, a obra literária, enquanto instrumento dotado de peculiaridades estética e temática, pode estabelecer um diálogo com a sociedade (e a cultura) brasileira, especialmente se a questão for tratada no âmbito da representação do local. Considerando que a violência é um "elemento fundador" e que "a sociedade brasileira, hoje, vive e representa a sua sociedade, a sua existência, como sendo altamente violenta" (VELHO, 1994, p. 32), é possível observar que a narrativa do escritor alinha-se a essa configuração do social, discutindo, de forma crítica, essa problemática. Nesse sentido, o romance pode ser lido como instrumento de reflexão quanto ao processo contínuo de experiências de violência na sociedade brasileira, fazendo alusão ao fato de que a história do Brasil é cheia de violências e que a literatura assume o papel de (re)contar, através da arte, esse traço característico da sociedade.

Ao discutir a representação do social na prosa de Sérgio Sant'Anna, Rosa de Carvalho afirma que o autor explora artifícios estéticos para compor o cenários da sociedade brasileira, pois

\begin{abstract}
Sérgio Sant'Anna trabalha sistematicamente sobre o fenômeno textual, evidenciando as possibilidades de construção da narrativa. Explora a crise de valores, a falência social, a ruína humana, erigindo sua linguagem a partir de uma atitude de desmascaramento do código. $\mathrm{Na}$ base de sua ficção, as marcas da sociedade brasileira, a serem despojadas e perturbadas. Nada de relíquias do Brasil, mas uma obra ligada ao país, em crise (1981, p. 34-35).
\end{abstract}

Assim, o escritor consegue em Confissões de Ralfo integrar à história do personagem história cultural urbana, produzindo representações da cidade que traduzem sensibilidades e sociabilidades do homem no contexto da cidade moderna. Sob este ponto de vista, "a literatura , como representação das formas urbanas, tem o poder metafórico de conferir aos lugares um sentido e uma função" (MARCEL apud PESAVENTO, 1999, p. 13). Ou seja, as histórias de Ralfo mostram que o caos aparente das cenas e da ordem em que são relatadas apresenta relação com a forma de narrar no contexto moderno e com a própria constituição da cidade e do homem neste contexto. A função, portanto, da literatura pode ser vista como a de mostrar, através da fragmentação, uma cidade, cujo sentido aproxima-se das dissonâncias, da dificuldade de se ter uma vida tranqüila e de o sujeito ser uno. 


\section{Referências}

ADORNO, Theodor. Teoria Estética. Tradução de Artur Morão. Lisboa: Edições 70, 1982.

CARVALHO, Rosa Maria Dizero de. A rota da desordem: uma leitura de "Confissões de Ralfo" e "Simulacros". Dissertação de mestrado (Programas de Pós-Graduação da Faculdade de Letras) - Universidade Federal do Rio de Janeiro, Rio de Janeiro, 1981.

GINZBURG, Jaime. A violência constitutiva: notas sobre autoritarismo e literatura no Brasil. Letras: Revista do Curso de Mestrado em Letras da Universidade Federal de Santa Maria, Santa Maria, n. 18/19, jan/dez, 1999, p. 121-144.

GORELIK, Adrián. O moderno em debate: cidade, modernidade, modernização. In: MIRANDA, Wander Melo (org.). Narrativas da modernidade. Belo Horizonte: Autêntica, 1999.

GUIDUCCI, Roberto. A cidade dos cidadãos: um urbanismo para todos. São Paulo: Brasiliense, 1980.

LYNCH, Kevin. A cidade como meio ambiente. In: DAVIS, Kingley et al. Cidades: a urbanização da humanidade. tradução de José Reznik. Rio de Janeiro: Zahar Editores, 1972. p. 207-216.

PESAVENTO, Sandra Jatahy. O imaginário da cidade: visões literárias do urbano: Paris, Rio de Janeiro, Porto Alegre. Porto Alegre: UFRGS, 1999.

ROSENFELD, Anatol. Reflexões sobre o romance moderno. In: . Texto/Contexto. São Paulo: Perspectiva, 1996.

SANT'ANNA, Sérgio. Confissões de Ralfo: uma autobiografia imaginária. Rio de Janeiro: Relume-Dumará, 1995.

SELIGMANN-SILVA, Márcio. Crítica e rememoração. Cult, Rio de Janeiro, n.72, 2003, p.42-50.

SHOLLHAMMER, Karl Erik. Os cenários urbanos da violência na literatura brasileira. In: PEREIRA, Carlos Alberto (org). Linguagens da violência. Rio de Janeiro: Rocco, 2000.

SILVERMAN, Malcolm. Moderna ficção brasileira 2. Tradução de João Guilherme Linke. Rio de Janeiro: Civilização Brasileira; Brasília/ INL, 1981. 